\title{
Novel Insights Into Gas Embolism in Sea Turtles: First Description in Three New Species
}

\section{OPEN ACCESS}

Edited by:

Peter H. Dutton,

Southwest Fisheries Science Center

(NOAA), United States

Reviewed by:

Thierry Work,

United States Geological Survey (USGS), United States Kara Dodge, New England Aquarium, United States

*Correspondence:

Jose L. Crespo-Picazo jlcrespo@oceanografic.org

Specialty section: This article was submitted to Marine Conservation

and Sustainability, a section of the journal Frontiers in Marine Science

Received: 18 February 2020 Accepted: 20 May 2020 Published: 12 June 2020

Citation: Crespo-Picazo JL, Parga M, Bernaldo de Quirós Y, Monteiro D, Marco-Cabedo V, Llopis-Belenguer C and García-Párraga D (2020) Novel Insights Into Gas Embolism in Sea

Turtles: First Description in Three New Species. Front. Mar. Sci. 7:442. doi: 10.3389/fmars.2020.00442

\section{Jose L. Crespo-Picazo ${ }^{*}$, Mariluz Parga ${ }^{2}$, Yara Bernaldo de Quirós ${ }^{3}$, Danielle Monteiro ${ }^{4}$, Vicente Marco-Cabedo', Cristina Llopis-Belenguer ${ }^{1,5}$ and Daniel García-Párraga1}

${ }^{1}$ Fundación Oceanogràfic de la Comunidad Valenciana, Valencia, Spain, ${ }^{2}$ SUBMON Associació, Barcelona, Spain, ${ }^{3}$ Atlantic Center for Cetacean Research, Institute of Animal Health and Food Safety (IUSA), Veterinary School, University of Las Palmas de Gran Canaria, Las Palmas, Spain, ${ }^{4}$ Projeto Tartarugas no Mar. Núcleo de Educação e Monitoramento Ambiental, Rio Grande, Brazil, ${ }^{5}$ Symbiosis Lab, Cavanilles Institute of Biodiversity and Evolutionary Biology, University of Valencia, Valencia, Spain

The recent finding of gas embolism (GE) and decompression sickness (DCS) in loggerhead sea turtles (Caretta caretta) in the Mediterranean Sea challenged the conventional understanding of marine vertebrate diving physiology. Additionally, it brought to light a previously unknown source of mortality associated with fisheries bycatch for this vulnerable species. In this paper, we use ultrasonography to describe GE in a leatherback sea turtle (Dermochelys coriacea), a green sea turtle (Chelonia mydas), and an olive ridley sea turtle (Lepidochelys olivacea) from accidental capture in a gillnet, bottom trawl, and pair-bottom trawl, respectively. This is the first description of this condition in these three species worldwide. These cases of GE suggest that this may be a threat faced by all sea turtle species globally.

Keywords: sea turtle, gas embolism, decompression sickness, fisheries, bycatch

\section{INTRODUCTION}

The incidental capture of sea turtles by fisheries, referred to as bycatch, is recognized as the greatest threat for the conservation of the species within this group worldwide (Wallace et al., 2010). Currently, six out the seven sea turtle species are listed by the International Union for Conservation of Nature as vulnerable, endangered, or critically endangered ${ }^{1}$ (accessed 28 April 2020). Despite this, accurate assessment of the global effects of bycatch is extremely challenging (Lewison et al., 2004). The size of global fishing fleet is too numerous to be monitored effectively, especially considering that much fishing occurs in international waters and many undocumented boats (Lewison et al., 2014). To address the issue of sea turtle bycatch therefore requires research and collaborative efforts among scientist, conservationists, industry, and managers (Lewison et al., 2004). The annual average number of sea turtle bycatch reported globally between 1990 and 2008 was 4722 turtles, but estimations of true total bycatch numbers are of two orders of magnitude higher given that only $1 \%$ of fleets report these data (Wallace et al., 2010).

A review of sea turtle bycatch in the Mediterranean Sea estimated over 132,000 captures and 44,000 mortalities per year (Casale, 2011). The fishing gear that caused the most captures was pelagic longline, followed by bottom trawl, setnets (single netting wall set stationary on the bottom),

${ }^{1}$ www.iucnredlist.org 
and gillnets (single, double, or triple walls near the surface, in midwater or on the bottom mounted together on the same frame ropes; FAO, 2001), and demersal longline, but set nets and gillnet resulted in higher mortalities than bottom trawlers (Casale, 2011). In the Atlantic Ocean, the trawl fishery industry in Gabon is responsible for an estimated annual bycatch of around 1026 olive ridley turtles with an estimated mortality ranging from 63 to 794 turtles per year, endangering the local breeding population (Casale et al., 2017). In the Pacific Ocean, mortalities of leatherback sea turtles by swordfish gillnet fisheries in Chile and Peru have contributed to the collapse of the Mexican Pacific coast breeding colony (Oravetz, 1999; Spolita et al., 2000).

In a global assessment of sea turtle bycatch in different gear, mortality rates were significantly higher in nets and trawls than longlines, emphasizing the need to mitigate bycatch impact by this gear (Wallace et al., 2013). Gear fixed to the bottom had higher mortality rates, although not statistically significant, when compared to gear used closer to the surface (Wallace et al., 2013). Some regions of the planet such as the southwest Atlantic Ocean and the Mediterranean Sea have been identify as "hotspots of bycatch intensity" for sea turtles (Lewison et al., 2014), although the authors highlight the widespread lack of data (Wallace et al., 2013).

It has traditionally been accepted that bycaught sea turtles either suffer from drowning and/or lesions caused by fishing gear (Casale, 2011). Recent research, however, has demonstrated that loggerhead sea turtles (Caretta caretta) caught by trawland gillnets have a high prevalence of intravascular gas or gas embolism (GE) (García-Párraga et al., 2014). Additionally, some of them presented clinical signs consistent with decompression sickness (DCS) (García-Párraga et al., 2014), a syndrome caused by the formation of intra- and extra-vascular gas bubbles when the summation of total dissolved gas exceeds local absolute pressure (Vann et al., 2011). In human hyperbaric medicine, Doppler flow transducers or two-dimensional echocardiography are the most common techniques used to detect intravascular gas bubbles (Mollerlokken et al., 2016). Although the detection of GE is not diagnostic of DCS, large bubble loads correlate with the probability of DCS (Evans et al., 1972; Neuman et al., 1976; Spencer, 1976; Gardette, 1979; Sawatzky, 1991), hence detection of GE by Doppler flow transducers or two-dimensional echocardiography are used as indicators of decompression stress (Pollock, 2007; Mollerlokken et al., 2016). The prevalence of GE in turtles caught accidentally in the waters of southern Brazil has recently been assessed onboard with surprising data on the development of intravascular gas in $100 \%$ of the individuals evaluated by ultrasonography (Parga et al., 2020).

In vitro studies of the vasoactive characteristics of the pulmonary and systemic arteries of loggerhead sea turtles suggest that nitrogen might accumulate and form gas bubbles as a result of an elevation of the sympathetic tone during the entanglement that, in turn, increases pulmonary blood flow and nitrogen uptake (García-Párraga et al., 2018). As this condition may affect post-release survivorship, this means the conventional estimates of bycatch mortality rates are underestimates. Thus, knowing the prevalence of GE and DCS in fisheries around the world is essential to quantify the true impact of fisheries bycatch on sea turtles worldwide.

To date, GE has mainly been recorded in loggerhead turtles in the Mediterranean yet there considering that sea turtle bycatch is a global problem for all sea turtle species, we postulate that this issue may be more widespread than currently thought. Here, we describe the diagnosis of GE in three sea turtle species, leatherback sea turtle (Dermochelys coriacea), green sea turtle (Chelonia mydas), and olive ridley (Lepidochelys olivacea) for which this has never been described before. This variety on species together with the new description outside of the Mediterranean Sea highlights the relevance for its consideration in the assessment of the effects of bycatch on all sea turtles and management plans worldwide.

\section{MATERIALS AND METHODS}

In October 2015, a bottom trawler fishing boat caught a live leatherback sea turtle (Figure 1A) along the Spanish Mediterranean coast (Castelló de la Plana, $39^{\circ} 58^{\prime} 59.99^{\prime \prime} \mathrm{N}$, $\left.0^{\circ} 1^{\prime} 59.99^{\prime \prime} \mathrm{E}\right)$. In May 2016, a coastal gillnet caught a live green turtle (Figure 1C) off the Spanish Mediterranean coast (Perellonet, $39^{\circ} 18^{\prime} 26.068^{\prime \prime} \mathrm{N}, 0^{\circ} 17^{\prime} 47.049^{\prime \prime} \mathrm{W}$ ). Both animals received health examinations under the authorization of the "Conselleria d'Agricultura, Desenvolupament Rural, Emergència Climàtica i Transició Ecològica" to the Oceanogràfic Aquarium of the City of Arts and Sciences of Valencia for coordinating veterinary stranding response. The leatherback turtle was evaluated onboard once the fishing boat reached the harbor and then released back in the open ocean. The green turtle was transported and examined at the veterinary facilities of the Oceanogràfic aquarium. Additionally, in January 2017, a pairbottom trawler in the Southern Atlantic Ocean (off the coast of Southern Brazil), caught a live olive ridley turtle (Figure 1E). This animal received a health examination on deck as part of a study carried out specifically to assess the prevalence and immediate evolution of DCS in incidentally captured turtles under the permits 15962-6 and 15962-7 from the Brazilian government (Parga et al., 2020).

For each turtle, we measured minimum curved carapace length (CCLmin) from the nuchal notch to the posterior tip of the caudal scute (Wyneken, 2001) or peduncle (Robinson et al., 2017). Veterinary evaluation included routine physical and neurological examinations, blood analyses, and imaging studies (García-Párraga et al., 2014). A portable ultrasound machine [General Electric Logiq E Vet ultrasound (GE Medical Systems)] with commercial 4C-RS (convex) for large individuals and 8CRS (microconvex) and 12L-RS (linear) probes for small and medium size was used to evaluate kidney area (Figure 1A), cardiac chambers, major vessels at the base of the heart and liver in smaller animals where the ultrasound beam had enough penetration. A convex probe was placed in the prefemoral acoustic window of the inguinal area in the leatherback turtle with a penetration depth of $20 \mathrm{~cm}$ to reach kidney and adjacent vessels. A linear probe was used for kidney in the green turtle and olive ridley (4-6 $\mathrm{cm}$ penetration depth) and a microconvex 

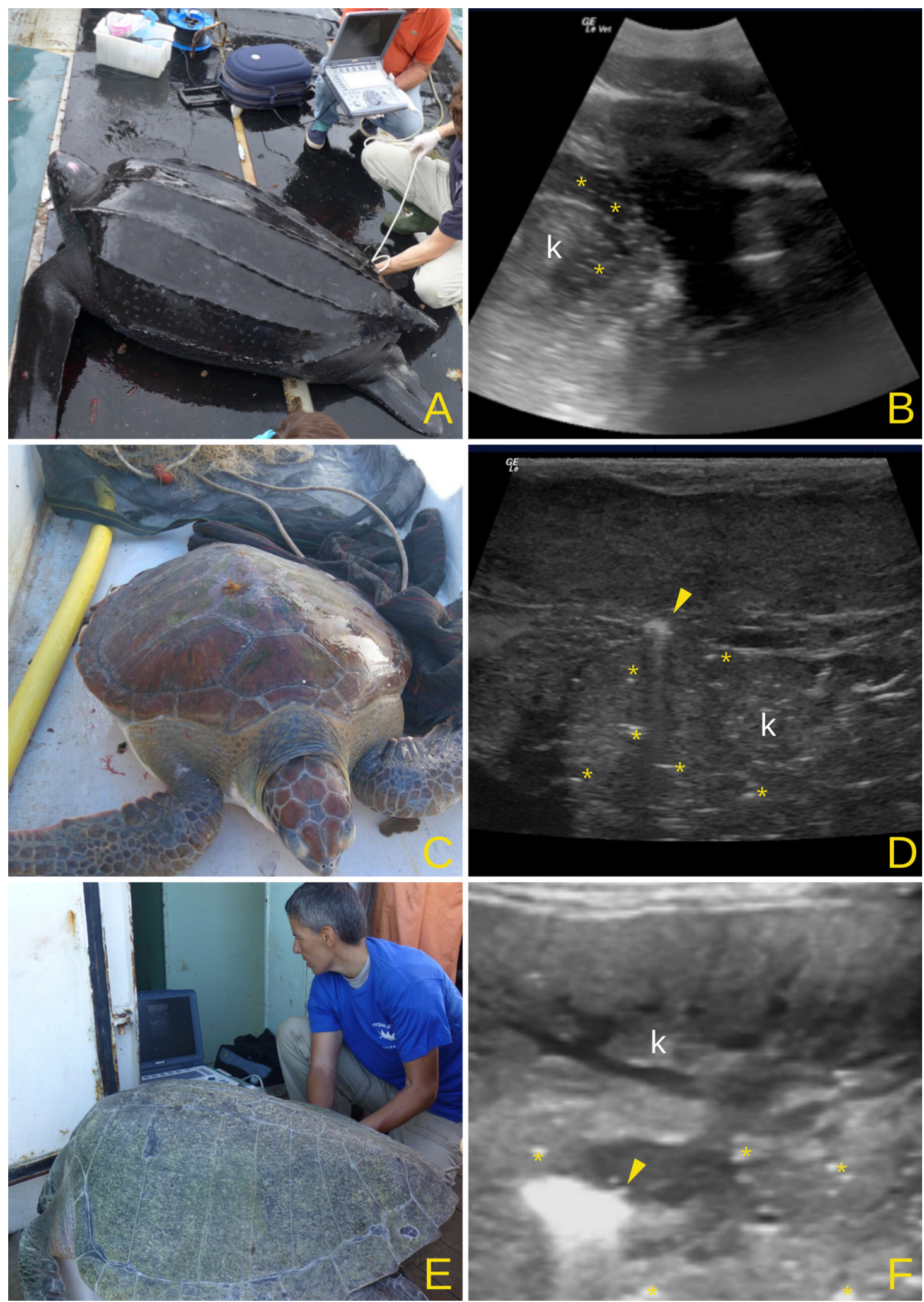

FIGURE 1 | Leatherback turtle (A), green turtle (C), and olive ridley (E) on the deck of the fishing boats. Kidney (K) ultrasound in the leatherback (B), green (D), and olive ridley (F) turtles showing the presence of gas as a hyperechoic (white) artifacts. Asterisks mark intravascular (B) or intra-parenchymal (D,F) gas seen as small hyperechogenic spots (small bubbles). Larger accumulations of gas usually produce comet tail artifacts on ultrasound examination (arrowhead). 
probe to reach liver, heart, and great vessels in the green turtle $(8-10 \mathrm{~cm}$ of penetration depth). In the three animals, the degree of GE was evaluated through ultrasound following the protocols outlined in García-Párraga et al. (2014). Based on the amount of gas detected in blood vessels and the distribution in the different organs, each turtle was categorized as: (1) mild embolism-a small amount of gas in kidneys, mainly small hyperecogenic spots moving through renal vessels and/or in renal parenchyma, few comet tail artifacts; (2) moderate embolism-a larger amount of gas in kidneys, with clear aggregation of gas in some vessels areas and evident comet tail artifacts, and presence of gas in liver and cardiac chambers; (3) severe embolism-a large amount of gas present in tissues hampering the ultrasound examination. Additionally to the ultrasound, the green turtle was also evaluated through radiography as described in GarcíaPárraga et al. (2014). Severity of the embolism was determined for the olive ridley on necropsy as the animal died onboard $2 \mathrm{~h}$ after surfacing.

\section{RESULTS}

\section{Leatherback Sea Turtle}

The CCLmin of this turtle was $136 \mathrm{~cm}$, corresponding to a subadult (Stewart et al., 2007). The accidental capture occurred during the $2.5 \mathrm{~h}$ trawl at $37 \mathrm{~m}$ deep. Physical examination was conducted on board about $4 \mathrm{~h}$ after surfacing, revealing mild bleeding abrasions on front flippers and dorsal keels, but no other significant lesions or scars were found. The animal was in good body condition, with evident fat accumulation on the neck, pectoral, and inguinal fossa, and was well hydrated. No abnormal behavioral responses were observed during physical or neurological examinations. Prefemoral ultrasound examination revealed hyperechogenic spots and comet tail artifacts in renal vessels and portal-renal vein compatible with intravascular gas bubbles (Figure 1B) (Crespo-Picazo, 2019a). At the neck region, the dorso-cervical sinus did not show evidence of gas bubbles. No other internal structures were accessible due to the large size of the animal and limited penetration of the ultrasound. Based on the limited amount of intravascular gas present on accessible regions, it was presumed to be a mild GE case.

\section{Green Turtle}

The CCLmin of this turtle was $43 \mathrm{~cm}$, corresponding to a juvenile (Limpus and Walter, 1980). The gillnet where the turtle was captured was set at $5 \mathrm{~m}$ deep for $12 \mathrm{~h}$. Physical examination conducted $4 \mathrm{~h}$ after surfacing did not show any clinical signs or external lesions. Body condition was good. Ultrasound examination revealed circulating bubbles in the right atrium and renal adjacent vessels. The renal parenchyma also presented hyperechogenic spots with comet tail artifacts (Figure 1D) (Crespo-Picazo, 2019b). Conventional radiographs also revealed small amounts of gas in the kidney region. Based on these findings, it was classified as a mild GE case. The turtle remained in the rescue center facilities until complete rehabilitation and was released 6 weeks after admission.

\section{Olive Ridley Turtle}

The CCLmin of this turtle was $71.9 \mathrm{~cm}$, corresponding to an adult (Zug et al., 1998). Trawl conditions when captured were $19 \mathrm{~m}$ deep for $4.5 \mathrm{~h}$. Physical examination revealed several fresh superficial wounds caused by net entanglement, a ray sting embedded in the skin immediately lateral to the tail and a recent cloacal prolapse. Body condition was good. Hyperechogenic spots compatible with intravascular gas bubbles were evident in renal and neck vessels on the first ultrasound scan taken when the animal arrived on deck (Figures 1F, 2A) (Crespo-Picazo and Parga, 2019). In a second scan, 30 min later, gas bubbles were even more clearly detectable in the renal parenchyma and vessels (Figure 2B). One hour later, the amount of gas was so severe that it hampered the renal ultrasound examination (Figure 2C). Based on the amount of gas present, the animal was classified as a severe GE case. GE severity was confirmed during necropsy as the turtle died $2 \mathrm{~h}$ after surfacing. Main findings included abundant gas inside cardiac chambers, senus venosus, mesenteric veins, kidneys, spleen, and most of the vasculature of all other internal organs (Figure 3). Macroscopic lesions associated with circulatory failure due to impediment of regular blood flow were also detected in several organs and tissues including the intestinal tract (segmental congestion of the intestinal mucosa), kidneys (marked congestion in extensive areas of renal parenchyma), and lungs (congestion and hemorrhage in lung parenchyma), confirming not just the presence of GE but also DCS diagnosis. Necropsy was performed within $12 \mathrm{~h}$ post-mortem, which it was also confirmed that the turtle was an adult female with well-developed and apparently functional oviducts.

\section{DISCUSSION}

Gas embolism and DCS was originally described in loggerhead sea turtles recovered as bycatch from trawlers and gillnets of local fisheries off the east coast of Spain (García-Párraga et al., 2014). Here, we demonstrate that green, leatherback, and olive ridley turtles are also susceptible to GE after fisheries interactions. Despite only having a single representative from each of these new species, we postulate that this provides evidence that all sea turtle species may, in fact, be susceptible to GE, especially when forcibly submerged for prolonged periods of time. This conclusion is further supported by recent findings that have showed the high prevalence of GE in loggerhead turtles in the southern Atlantic (Parga et al., 2020). Overall, we therefore think that GE may be a severely underestimated form of mortality associated with interactions between fisheries and sea turtles. If true, global estimates of sea turtle mortality associated with fisheries bycatch (e.g., Lewison et al., 2004) may be far higher than initially predicted.

Leatherbacks are the deepest diving sea turtle species, and therefore are the most adapted to deal with the associated effects of decompression after diving (Davenport et al., 2009; Fossette et al., 2010; Murphy et al., 2012). Yet, we still found evidence that this species is also affected by GE when forcibly submerged. Furthermore, this occurred when this individual was caught as a relatively shallow depth $(37 \mathrm{~m})$, which is shallower than the 


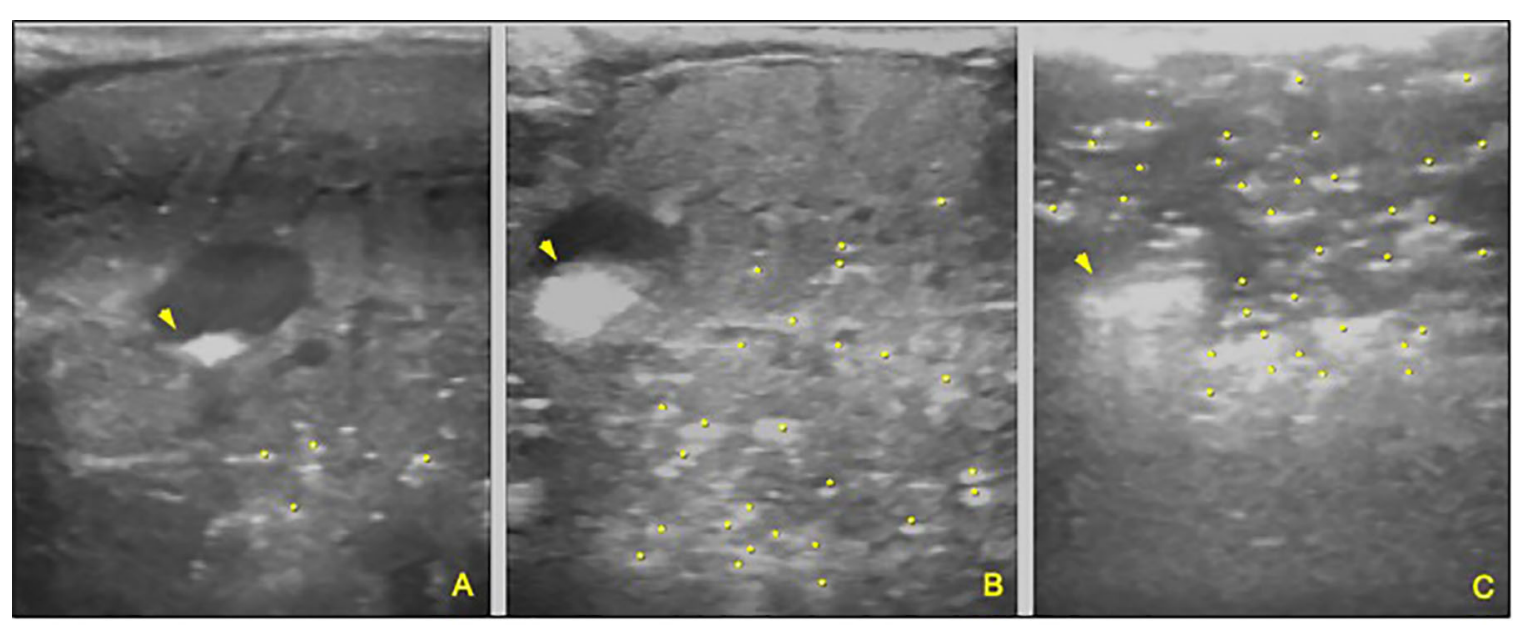

FIGURE 2 | Sequence of ultrasound images of the renal area of the olive ridley turtle, within 30-40 min intervals. A clear increase in the presence of gas in vessels and renal parenchyma is observed. (A) Mild gas embolism. Initial ultrasound after approximately 20 min of being surfaced. (B) Moderate gas embolism: The amount and distribution of gas increase in blood vessels and renal parenchyma. (C) Severe gas embolism. Massive amount of gas preventing ultrasound penetration and tissue visualization.

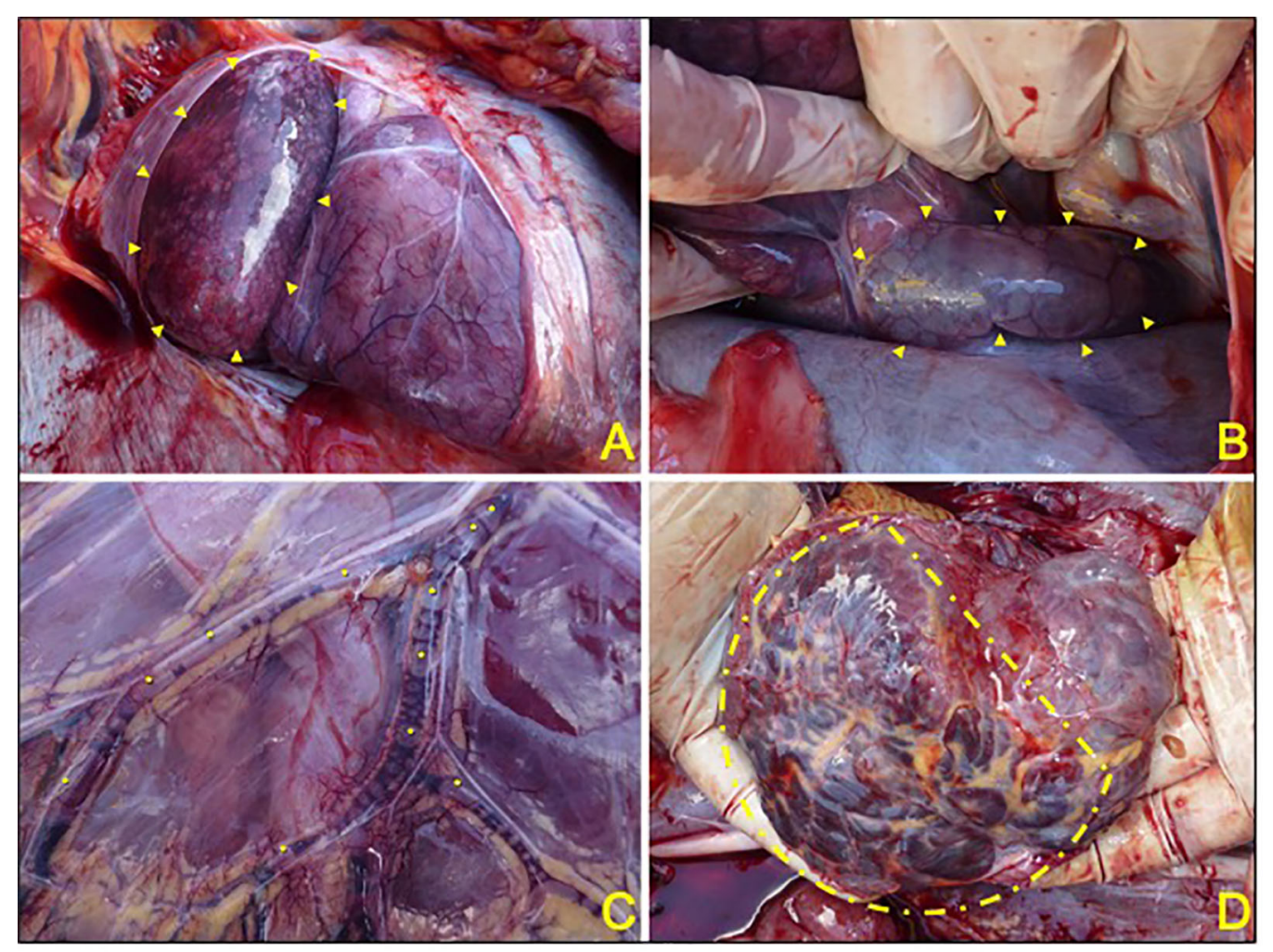

FIGURE 3 | Selected images from the olive ridley turtle necropsy affected with severe GE and DCS. (A) Opening of the pericardium, abundant gas bubbles are observed in the right atrium (arrowheads). (B) Large presence of gas in the venous sinus (arrowheads). (C) Presence of gas bubbles (asterisks) in mesenteric veins. (D) Marked congestion (dotted line area) of the renal parenchyma.

mean dive depth for this species (Robinson and Paladino, 2015). If leatherback turtles, a species that has been recorded dive to depths over $1200 \mathrm{~m}$ (Houghton et al., 2008), are affected by GE when retained at such shallow depths, it might suggest that all species of sea turtle may be vulnerable to GE. Alteration of the physiologic mechanism to minimize nitrogen absorption during dives (bradycardia, intracardiac shunting, pulmonary sphincters) is considered the main physio-pathological explanation driving 
GE formation (García-Párraga et al., 2018). These anatomical, physiological, and behavioral mechanisms have been identified and developed to a different degree in several sea turtles species (Sapsford, 1978; García-Párraga et al., 2017). Although most work until now has been based on loggerheads as they are the most common bycaught species in the western Mediterranean, based on the present work, we cannot exclude all other species of sea turtles for being potentially affected from decompression under entanglement conditions at depth.

All three species described here appeared to suffer GE, but only the olive ridley was confirmed to have symptoms and lesions of DCS. As these symptoms and lesions were identical to those found in loggerhead turtles (García-Párraga et al., 2014), this provides further support that GE might be a common threat to all sea turtle species. Nevertheless, further research is still needed to confirm if this is the case and the real risk for the detected intravascular gas bubbles to lead to actual DCS and potential subsequent death in all other species. Perhaps some sea turtle species are able to manage any GE and thus inhibit the occurrence of any pathological events. Identifying more cases over time in different species and under different fisheries and environmental conditions will help clarify clinical implications and susceptibility to disease in the different species of sea turtles. Additionally, further investigations should also determine the role of concurrent and cumulative deleterious effects of other metabolic disorders observed in accidentally and direct capture of sea turtles (Harms et al., 2003; Innis et al., 2010, 2014; Phillips et al., 2015).

\section{Conservation Implications}

Mortality due to fishery interaction can be divided into direct and delayed mortality (Parga et al., 2017). The former is relatively easy to ascertain as it can be observed directly, given that it happens at the time of incidental capture or immediately after, with the animal still on board the fishing vessel. Delayed mortality, however, is far more difficult to assess, as it may occur within hours, days, or even months after the release of the animal. Mortality rates are commonly calculated based on two scenarios: (a) the total number of caught turtles found dead in fishery gear (all comatose turtles are assumed to survive) and (b) the total number of caught turtles found dead or comatose (assuming eventual death) in fishery gear (Casale et al., 2017).

Despite little data being currently available on post-release survivorship (Swimmer et al., 2006; Maxwell et al., 2018; Parga et al., 2020), the IUCN sea turtle specialist group recommends that live and moving sea turtles should be released from the boat and reintroduced into the sea (Oravetz, 1999). As these animals are active on release, they are therefore not typically accounted for when calculating bycatch mortality rates. Our finding as well as those of previous studies, however, suggest some those turtles may die within hours or days post-release (García-Párraga et al., 2014; Parga et al., 2020). Further knowledge on post-release survival is therefore essential to develop a more accurate measure of fisheries associated mortality in sea turtles.

It has been shown that the likelihood of fatal decompression in loggerhead sea turtles increases with gear depth; an average trawl depth of $65 \mathrm{~m}$ resulted in 50\% estimated mortality under particular conditions (Fahlman et al., 2017). This finding is in agreement with previous global mortality bycatch estimates, which suggested that gears fixed to the bottom had higher mortality rates than shallower gear (Wallace et al., 2013), except if those gears are at depths out of the normal sea turtle diving range. As such, within the sea turtle diving range, reducing gear deployment depth (when possible) and soak time might be a mitigation measure worth taking into consideration and thus merits further investigation. On the other hand, by deploying gear at depths that exceed the typical diving ranges of sea turtles would also minimize the probability of sea turtle capture.

\section{CONCLUSION}

We found evidence that at least four sea turtle species are susceptible to GE and/or DCS because of bycatch in gillnets and trawlers at different geographical locations. As this condition can lead to reduce survivorship, there is a vital need for further studies to assess the prevalence of DCS in sea turtles for all fisheries and all sea turtle species worldwide. In turn, this knowledge will help both improve estimates of fisheries associated mortality in sea turtles and guide conservation management actions (Lewison et al., 2004). Research into effective mitigation measures and their implementation should continue with particular consideration of fishing gears types, deployment depths, soaking times, and locations that are more likely to result in bycaught sea turtles remaining forcibly submerged and developing GE and/or DCS.

\section{DATA AVAILABILITY STATEMENT}

All datasets generated for this study are included in the article/supplementary material.

\section{ETHICS STATEMENT}

Turtle health examinations were performed under the authorization of the "Valencia Ministry of Agriculture, Rural Development, Climate Emergency and Ecological Transition" to the Oceanogràic Aquarium of the City of Arts and Sciences of Valencia for coordinating veterinary stranding response. The study in Ocean Atlantic waters was specifically carried out to assess the prevalence and immediate evolution of DCS in incidentally captured turtles under the permits 15962-6 and 15962-7 from the Brazilian government. Handling and sampling protocols were based on NMFS-SEFSC 2008 Sea Turtle Research Techniques Manual. All procedures were performed in accordance with relevant guidelines and regulations.

\section{AUTHOR CONTRIBUTIONS}

JC-P conceived the presented idea. JC-P, MP, and DM did the field work and collected the data. YB, VM-C, and DG-P verified the analytical methods and supervised the findings of this work. 
JC-P and CL-B wrote the manuscript. All authors discussed the results and contributed to the final manuscript.

\section{FUNDING}

VM-C, JC-P, and DG-P were supported by Fundación Oceanogràfic and Avanqua-Oceanogrànic, respectively. MP and DM as well as research in Atlantic Ocean of this study were funded primarily by the U.S. National Oceanic and Atmospheric Administration (NOAA) Bycatch Reduction Engineering Program and Brazil's Petrobras. CL-B was supported by a contract from Conselleria d' Educació, Cultura i Esport (Generalitat Valenciana, Spain) and the European Social Fund (FSE) (ACIF/2016/374).

\section{REFERENCES}

Casale, P. (2011). Sea turtle by-catch in the Mediterranean: sea turtle by-catch in the Mediterranean. Fish Fish. 12, 299-316. doi: 10.1111/j.1467-2979.2010. 00394.x

Casale, P., Abitsi, G., Aboro, M. P., Agamboue, P. D., Agbode, L., Allela, N. L., et al. (2017). A first estimate of sea turtle bycatch in the industrial trawling fishery of Gabon. Biodivers. Conserv. 26, 2421-2433. doi: 10.1007/s10531-017-1367-z

Crespo-Picazo, J. L. (2019a). Gas Embolism in a Leatherback Sea Turtle (Dermochelys coriacea) Ultrasound. Left and Right Inguinal Area. Figshare. doi: 10.6084/m9.figshare.11435034.v1

Crespo-Picazo, J. L. (2019b). Gas Embolism in a Juvenile Green Sea Turtle (Chelonia mydas). Kidney Ultrasound. Figshare. doi: 10.6084/m9.figshare.11441148.v1

Crespo-Picazo, J. L., and Parga, M. (2019). Gas Embolism in an Adult Olive Ridley Sea Turtle (Lepidochelys olivacea). Kidney Examination. Figshare. doi: 10.6084/ m9.figshare.11445126.v1

Davenport, J., Fraher, J., Fitzgerald, E., McLaughlin, P., Doyle, T., Harman, L., et al. (2009). Ontogenetic changes in tracheal structure facilitate deep dives and cold water foraging in adult leatherback sea turtles. J. Exp. Biol. 212, 3440-3447. doi: $10.1242 /$ jeb.034991

Evans, A., Barnard, E. E. P., and Walder, D. N. (1972). Detection of gas bubbles in man at decompression. Aerosp. Med. 43, 1095-1096.

Fahlman, A., Crespo-Picazo, J. L., Sterba-Boatwright, B., Stacy, B. A., and GarciaParraga, D. (2017). Defining risk variables causing gas embolism in loggerhead sea turtles (Caretta caretta) caught in trawls and gillnets. Sci. Rep. 7:2739. doi: 10.1038/s41598-017-02819-5

FAO (2001). Fishing Gear types. Gillnets and Entangling Nets. Technology Fact Sheets. [WWW Document]. Rome: FAO Fisheries and Aquaculture Department.

Fossette, S., Gleiss, A. C., Myers, A. E., Garner, S., Liebsch, N., Whitney, N. M., et al. (2010). Behaviour and buoyancy regulation in the deepest-diving reptile: the leatherback turtle. J. Exp. Biol. 213, 4074-4083. doi: 10.1242/jeb.048207

García-Párraga, D., Crespo-Picazo, J., de Quirós, Y., Cervera, V., Martí-Bonmati, L., Díaz-Delgado, J., et al. (2014). Decompression sickness ('the bends') in sea turtles. Dis. Aquat. Org. 111, 191-205. doi: 10.3354/dao02790

García-Párraga, D., Lorenzo, T., Wang, T., Ortiz, J.-L., Ortega, J., Crespo-Picazo, J.-L., et al. (2018). Deciphering function of the pulmonary arterial sphincters in loggerhead sea turtles (Caretta caretta). J. Exp. Biol. 221:jeb179820. doi: 10.1242/jeb.179820

García-Párraga, D., Valente, A. L. S., Stacy, B. A., and Wyneken, J. (2017). "Cardiovascular system," in Sea Turtle Health and Rehabilitation, ed. C. A. Manire (Plantation, FL: J. Ross Publishing), 295-320.

Gardette, B. (1979). Correlation between decompression-sickness and circulating bubbles in 232 divers. Undersea Biomed. Res. 6, 99-107.

Harms, C. A., Mallo, K. M., Ross, P. M., and Segars, A. (2003). Venous blood gases and lactates of wild loggerhead sea turtles (Caretta caretta) following two capture techniques. J. Wildl. Dis. 39, 366-374. doi: 10.7589/0090-3558-39.2.366

Houghton, J. D. R., Doyle, T. K., Davenport, J., Wilson, R. P., and Hays, G. C. (2008). The role of infrequent and extraordinary deep dives in leatherback

\section{ACKNOWLEDGMENTS}

We thank all professionals at the Oceanogràfic, especially at the ARCA Rehabilitation Center, for their many efforts and complete dedication to the best animal care. In particular, we are grateful to all the fishermen contributing to the project as well as to the Conselleria d'Agricultura, Desenvolupament Rural, Emergència Climàtica i Transició Ecològica of the Valencia Community Regional Government. We also thank SCilVet for lending the ultrasound unit used during the first field trip and ZOETIS Spain for supporting veterinary diagnosis and stranding medical response. Special thanks to Alex Arkwright and Nathan Robinson for their independent review of the draft and all their suggestions.

turtles (Dermochelys coriacea). J. Exp. Biol. 211, 2566-2575. doi: 10.1242/jeb. 020065

Innis, C., Merigo, C., Dodge, K., Tlusty, M., Dodge, M., Sharp, B., et al. (2010). Health evaluation of leatherback turtles (Dermochelys coriacea) in the Northwestern Atlantic during direct capture and fisheries gear disentanglement. Chel. Conserv. Biol. 9, 205-222. doi: 10.2744/CCB0838.1

Innis, C. J., Merigo, C., Cavin, J. M., Hunt, K., Dodge, K. L., and Lutcavage, M. (2014). Serial assessment of the physiological status of leatherback turtles (Dermochelys coriacea) during direct capture events in the northwestern Atlantic Ocean: comparison of post-capture and pre-release data. Conserv. Physiol. 2:cou048. doi: 10.1093/conphys/cou048

Lewison, R., Crowder, L., Read, A., and Freeman, S. (2004). Understanding impacts of fisheries bycatch on marine megafauna. Trends Ecol. Evol. 19, 598-604. doi: 10.1016/j.tree.2004.09.004

Lewison, R. L., Crowder, L. B., Wallace, B. P., Moore, J. E., Cox, T., Zydelis, R., et al. (2014). Global patterns of marine mammal, seabird, and sea turtle bycatch reveal taxa-specific and cumulative megafauna hotspots. Proc. Natl. Acad. Sci. U.S.A. 111, 5271-5276. doi: 10.1073/pnas.1318960111

Limpus, C. J., and Walter, D. G. (1980). The growth of immature green turtles (Chelonia mydas) under natural conditions. Herpetologica 36, 162-165.

Maxwell, S. M., Witt, M. J., Abitsi, G., Aboro, M. P., Agamboue, P. D., Asseko, G. M., et al. (2018). Sea turtles and survivability in demersal trawl fisheries: do comatose olive ridley sea turtles survive post-release? Anim. Biotelemetry 6:11. doi: 10.1186/s40317-018-0155-1

Mollerlokken, A., Blogg, S. L., Doolette, D. J., Nishi, R. Y., and Pollock, N. W. (2016). Consensus guidelines for the use of ultrasound for diving research. Div. Hyperbaric Med. 46, 26-32.

Murphy, C., Kelliher, D., and Davenport, J. (2012). Shape and material characteristics of the trachea in the leatherback sea turtle promote progressive collapse and reinflation during dives. J. Exp. Biol. 215, 3064-3071. doi: 10.1242/ jeb.072108

Neuman, T. S., Hall, D. A., and Linaweaver, P. G. (1976). Gas phase separation during decompression in man: ultrasound monitoring. Undersea Biomed. Res. $3,121-130$.

Oravetz, C. A. (1999). "Reducing incidental catch in fisheries," in Research and Management Techniques for the Conservation of Sea Turtles, eds K. L. Eckert, K. A. Bjorndal, F. A. Abreu-Grobois, and M. Donnelly (Washington, DC: IUCN/SSC Marine Turtle Specialist Group).

Parga, M., Crespo-Picazo, J., García-Párraga, D., Stacy, B. A., and Harms, C. A. (2017). "Fisheries and sea turtles," in Sea Turtle Health \& Rehabilitation, ed. C. A. Manire (Plantation, FL: J. Ross Publishing).

Parga, M. L., Crespo-Picazo, J. L., Monteiro, D., García-Párraga, D., Hernandez, J. A., Swimmer, Y., et al. (2020). On-board study of gas embolism in marine turtles caught in bottom trawl fisheries in the Atlantic Ocean. Sci. Rep. 10:5561. doi: 10.1038/s41598-020-62355-7

Phillips, B. E., Cannizzo, S. A., Godfrey, M. H., Stacy, B. A., and Harms, C. A. (2015). Exertional myopathy in a juvenile green sea turtle (Chelonia mydas) 
entangled in a large mesh gillnet. Case Rep. Vet. Med. 2015, 1-6. doi: 10.1155/ $2015 / 604320$

Pollock, N. W. (2007). Use of ultrasound in decompression research. Div. Hyperbaric Med. 37, 68-72.

Robinson, N. R., and Paladino, F. V. (2015). “The diving behavior and physiology of the leatherback turtle," in The Leatherback Turtle: Biology and Conservation, eds J. R. Spotila, and P. S. Tomillo (Baltimore, MD: The Johns Hopkins University Press).

Robinson, N. R., Stewart, K. R., Dutton, P. H., Nel, R., Paladino, F. V., and Santidrian Tomillo, P. (2017). Standardising curved carapace length measurements for leatherback turtles, Dermochelys coriacea, to investigate global patterns in body size. Herpetol. J. 27, 231-234.

Sapsford, C. W. (1978). Anatomical evidence for intracardiac blood shunting in marine turtles. Zool. Afr. 13, 57-62. doi: 10.1080/00445096.1978.1144 7605

Sawatzky, K. D. (1991). The Relationship Between Intravascular Doopler-Detected Gas Bubbles and Decompression Sickness after Bounce Diving in Humans. Ph. D. Thesis, York University, Toronto, ON.

Spencer, M. P. (1976). Decompression limits for compressed air determined by ultrasonically detected blood bubbles. J. Appl. Physiol. 40, 229-235. doi: 10. 1152/jappl.1976.40.2.229

Spolita, J., Reina, R., Steyermark, A., Plotkin, P., and Paladino, F. (2000). Pacific leatherback turtles face extinction. Nature 405, 529-530. doi: 10.1038/35014729

Stewart, K., Johnson, C., and Godfrey, M. H. (2007). The minimum size of leatherbacks at reproductive maturity, with a review of sizes for nesting females from the Indian, Atlantic and Pacific Ocean basins. Herpetol. J. 17, 123-128.

Swimmer, Y., Arauz, R., McCracken, M., McNaughton, L., Ballestero, J., Musyl, M., et al. (2006). Diving behavior and delayed mortality of olive ridley sea turtles
Lepidochelys olivacea after their release from longline fishing gear. Mar. Ecol. Prog. Ser. 323, 253-261. doi: 10.3354/meps323253

Vann, R. D., Butler, F. K., Mitchell, S. J., and Moon, R. E. (2011). Decompression illness. Lancet 377, 153-164. doi: 10.1016/S0140-6736(10)61085-9

Wallace, B. P., Kot, C. Y., DiMatteo, A. D., Lee, T., Crowder, L. B., and Lewison, R. L. (2013). Impacts of fisheries bycatch on marine turtle populations worldwide: toward conservation and research priorities. Ecosphere 4:art40. doi: 10.1890/ES12-00388.1

Wallace, B. P., Lewison, R. L., McDonald, S. L., McDonald, R. K., Kot, C. Y., Kelez, S., et al. (2010). Global patterns of marine turtle bycatch: global patterns of marine turtle bycatch. Conserv. Lett. 3, 131-142. doi: 10.1111/j.1755-263X.2010. 00105.x

Wyneken, J. (2001). The Anatomy of Sea Turtles. U.S. Department of Commerce NOAA Technical Memorandum NMFS-SEFSC-470, 172.

Zug, G. R., Wilson, R. V., and Ernst, C. H. (1998). Lepidochelys olivacea. Cat. Am. Amphib. Rept. 653, 1-13.

Conflict of Interest: The authors declare that the research was conducted in the absence of any commercial or financial relationships that could be construed as a potential conflict of interest.

Copyright (C) 2020 Crespo-Picazo, Parga, Bernaldo de Quirós, Monteiro, MarcoCabedo, Llopis-Belenguer and García-Párraga. This is an open-access article distributed under the terms of the Creative Commons Attribution License (CC BY). The use, distribution or reproduction in other forums is permitted, provided the original author(s) and the copyright owner(s) are credited and that the original publication in this journal is cited, in accordance with accepted academic practice. No use, distribution or reproduction is permitted which does not comply with these terms. 